\section{The Future of Geriatric Oncology Research: Moving Toward Interventions and Objective Biomarkers of Aging}

\author{
Efrat Dotan, MD
}

S ignificant progress has been made in the field of geriatric oncology in recent years with the development and validation of a cancer-specific geriatric assessment (GA), establishing chemotherapy toxicity prediction tools, and geriatric screening tools that could be easily incorporated into a busy oncology practice. ${ }^{1}$ With strong advocacy from guidelines, the oncologic community has begun to acknowledge the utility of these tools and explore their incorporation into the care of older adults with cancer. As we aspire to advance the field of geriatric oncology, it is time to think beyond assessments and focus research efforts on interventions and novel objective methods to evaluate patients.

In this issue of JNCCN, Rosko et al ${ }^{2}$ present a pilot study focused on testing an exercise intervention aimed at improving functional status of older adults with hematologic malignancies receiving active therapy. Enrolled patients completed a GA, quality-of-life (QoL) evaluation, an objective measurement of function with Short Physical Performance Battery at baseline, and 4 and 6 months of the Otago Exercise Programme (OEP). Thirty patients with a median age of 75 years, most of whom were treated for plasma cell dyscrasia, were enrolled. Participants showed improvement in functional status, physical health scores, patient-reported Karnofsky performance status, Short Physical Performance Battery score, and QoL after the exercise intervention. These results demonstrate the ability of a proactive exercise program to mitigate functional decline and improve QoL during intense anticancer treatments.

Cancer diagnosis and treatments can have detrimental effects on the functional status of older adults, increasing the risks of falls, loss of independence, and frailty. ${ }^{3}$ Hence, proactive evaluation of functional status and appropriate interventions (eg, referral to physical and occupational therapy) have been proposed by guidelines. ${ }^{4,5}$ The Otago Exercise Programme was designed as a strength and balance retraining program aimed at preventimg falls in community elders, and has been shown to reduce risk of falls and death among these individuals. ${ }^{6}$ Furthermore, this intervention has been shown to improve static, dynamic, proactive, and perceived balance among the general older population. ${ }^{7}$ This intervention has not been widely tested among geriatric oncology patients; nonetheless, in this study it resulted in significant benefit for older adults with hematologic malignancies. Prior studies among patients with cancer reported improvement in treatment tolerance, cancer-related fatigue, and CoL with participation in exercise programs during therapy. ${ }^{8}$ A few studies evaluating exercise programs specifically among older adults with cancer have shown improvement in anxiety, mood, self-reported health, and symptoms. The data presented in this manuscript add to the growing body of evidence supporting the inclusion of exercise programs in the management of older adults with cancer. It underscores the need for additional research to define the most effective exercise structure, frequency, and intensity for these patients. This opens a new era of research in the geriatric oncology field focused on active interventions tailored for older adults, their specific cancer diagnosis, and prescribed anticancer therapy.

See page 1027 for related article.

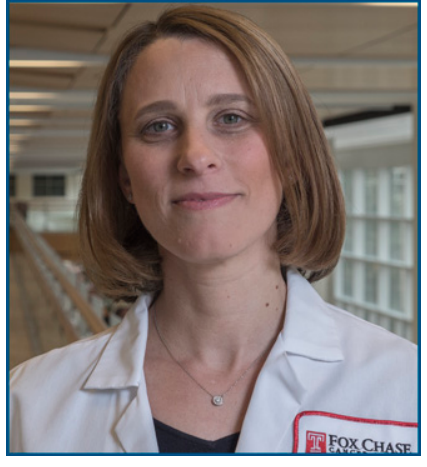

\section{EFRAT DOTAN, MD}

Efrat Dotan, MD, is an Associate Professor of Medical Oncology and the Division Chief of the Gastrointestinal Cancer Program at Fox Chase Cancer Center.

Dr. Dotan specializes in the management of patients with gastrointestinal malignancies with a focus on the care of older patients with gastrointestinal cancers. Her research focuses on clinical trials investigating new treatment approaches for gastrointestinal malignancies, specifically pancreatic cancer; the development of tools to improve the assessment and care of older adults with cancer; and investigating novel treatment approaches for this patient population.

Dr. Dotan is the chair of the NCCN Guidelines Panel for Older Adult Oncology and a member the NCCN Pancreatic Adenocarcinoma Panel. She is an active member of the ECOG

Gastrointestinal Malignancies Committee, serving as the principal investigator for a national elderly specific pancreatic cancer study. She also serves as a senior member of the Cancer and Aging Research Group and is the founder and chairs the ECOG Geriatric Oncology Working Group.

doi: 10.6004/jnccn.2021.7086

The ideas and viewpoints expressed in this commentary are those of the author and do not necessarily represent any policy, position, or program of NCCN. 
The exploratory analyses conducted during this study are also in line with the future directions of research in the field of geriatric oncology. The study included robust and repeated geriatric assessments. These assessments allowed for clustering of patients based on standardized values of each geriatric metric and identification of 3 categories of frailty. Furthermore, evaluation of molecular markers of aging in peripheral blood T-lymphocytes mRNA demonstrated an association between frailty and changes in T-cell immune profile. DNA extracted from peripheral blood mononuclear cells was also tested for epigenetic age, demonstrating a younger phenotypic age by epigenetic clocks compared with chronologic age in this cohort. Interestingly, patient's epigenetic age decreased or remained stable after the exercise intervention. Although these analyses were conducted on a small number of patients, which limits the ability to draw definitive conclusions, the results highlight the feasibility of obtaining objective biomarkers that can provide information on physiologic age and potentially guide treatment approach.

The aging process is complex, and chronologic age is a poor descriptor of the true physiologic age of an older patient. The GA is the gold standard tool for identification of age-related concerns that can predict survival and treatment tolerance. However, due to limited time and personnel, GA is not routinely used in most practices. Identification of an objective biomarker that can accurately determine the patient's true physiologic age could become a useful tool to help personalize therapy for older adults with cancer. Several biomarkers of aging have been studied in recent years, including inflammatory markers (eg, IL-6, C-reactive protein, tumor necrosis factor- $\alpha$, D-dimer), markers of cellular senescence (eg, $\left.\mathrm{P} 16^{\mathrm{INK}} 4 \mathrm{~A}\right)$, and sarcopenia. These biomarkers demonstrated correlation with frailty, functional decline, and survival. ${ }^{9}$ However, a clear clinical role for these markers or combination of them has not been defined. Aging clocks (ie, epigenetic clocks and proteomic clocks) have also been evaluated, mostly in epidemiologic studies showing correlation with risk of cancer development. 9,10 Better understanding of these biomarkers and their ability to predict for treatment tolerance, chronic toxicities, functional decline, and overall survival would allow us to use them as clinical tools to personalize cancer treatment for older adults, maximizing efficacy while reducing deleterious effects.

Similarly, devices such as electronic fitness trackers have the potential to provide objective information regarding the functional status of an older adult and assist in treatment planning. ${ }^{11}$ These devices can also assist in monitoring and continuously evaluating patients during therapy, allowing for treatment adjustments, and even providing a personalized exercise prescription. The opportunity to have a thorough evaluation of patients outside their routine clinical visit can significantly increase the provider's ability to understand the patient's fitness and to provide enhanced support. Such intervention can result in significant improvement of outcomes for patients across the continuum of cancer care from active therapy to survivorship.

Rosko et $\mathrm{al}^{2}$ should be congratulated on moving the needle forward in geriatric oncology research from assessment to interventions and from subjective measures to objective biomarkers of aging. The positive outcomes seen with the use of this exercise intervention should be further studied in larger cohorts and in various cancers and treatment settings. In addition, studies evaluating the predictive and prognostic ability of novel biomarkers such as aging clocks are needed to determine whether these tools can be used clinically as quick and reliable objective assessments. As we continue to improve our evidence-based management of older adults with cancer, focusing our efforts in these two areas will result in further improvement in the care of this vulnerable patient population.

Disclosures: Dr. Dotan has disclosed receiving grant/research support from AstraZeneca Pharmaceuticals LP, Boston Biomedical, Eli Lilly and Company, Incyte Corporation, Ipsen, Medlmmune Inc., and Pfizer Inc.

Funding: Dr. Dotan is supported by a Cancer Center Support Grant 3 P30 CA006927.

Correspondence: Efrat Dotan, MD, Department of Hematology/Oncology, Fox Chase Cancer Center, 333 Cottman Avenue, Philadelphia, PA 19111. Email: efrat.dotan@fccc.edu

\section{References}

1. DuMontier C, Sedrak MS, Kheng Soo W, et al. Arti Hurria and the progress in integrating the geriatric assessment into oncology: Young International Society of Geriatric Oncology review paper. J Geriatr Oncol 2020;11:203-211.

2. Rosko $A E$, Wall $S$, Baiocchi $R$, et al. Aging phenotypes and restoring functional deficits in older adults with hematologic malignancy. J Natl Compr Canc Netw 2021;19:XXX-XXX.

3. Nightingale $G$, Battisti NML, Loh KP, et al. Perspectives on functional status in older adults with cancer: an interprofessional report from the International Society of Geriatric Oncology (SIOG) nursing and allied health interest group and young SIOG. J Geriatr Oncol 2021;12:658665 .

4. VanderWalde N, Jagsi R, Dotan E, et al. NCCN Guidelines Insights: Older Adult Oncology, Version 2.2016. J Natl Compr Canc Netw 2016; 14: 1357-1370.

5. Mohile SG, Dale W, Somerfiled MR, et al. Practical assessment and management of vulnerabilities in older patients receiving chemotherapy: ASCO Guideline for Geriatric Oncology. J Clin Oncol 2018;36:2326-2347.

6. Thomas S, Mackintosh S, Halbert J. Does the 'Otago exercise programme' reduce mortality and falls in older adults? A systematic review and meta-analysis. Age Ageing 2010;39:681-687.

7. Chiu HL, Yeh TT, Lo YT, et al. The effects of the Otago Exercise Programme on actual and perceived balance in older adults: a meta-analysis. PLoS One 2021;16:e0255780. 
8. Kleckner IR, Dunne RF, Asare M, et al. Exercise for toxicity management in cancer-a narrative review. Oncol Hematol Rev 2018;14:2837.

9. Hurria A, Jones L, Muss HB. Cancer treatment as an accelerated aging process: assessment, biomarkers, and interventions. Am Soc Clin Oncol Educ Book 2016;35:e516-522.
10. Wang S, Prizment A, Thyagarajan B, et al. Cancer treatment-induced accelerated aging in cancer survivors: biology and assessment. Cancers (Basel) 2021;13:427.

11. Ward WH, Meeker CR, Handorf E, et al. Feasibility of fitness tracker usage to assess activity level and toxicities in patients with colorectal cancer. JCO Clin Cancer Inform 2021;5:125-133.

\section{Statement of Ownership, Management and Circulation (Requester Publication)}

1. Publication Title: JNCCN_Journal of the National Comprehensive Cancer Network. 2. Publication Number: 1540-1405. 3) Filing Date: 9/15/2021. 4) Issue Frequency: Monthly, except semi-monthly in May. 5) Number of Issues Published Annually: 13 6) Annual Subscription Price (if any): \$1031.00. 7) Complete Mailing Address of Known Office of Publication: Harborside Press LLC, 94 North Woodhull Road, Huntington, Suffolk, NY 11743. Contact Person: John Gentile. Telephone: 631-935-7655. 8) Complete Mailing Address of Headquarters or General Business Office of Publisher: Harborside Press LLC, 94 North Woodhull Road, Huntington, Suffolk, NY 11743. 9) Full Names and Complete Mailing Addresses of Publisher, Editor, and Managing Director: Publisher: John A. Gentile Jr, Harborside Press LLC, 94 North Woodhull Road, Huntingont, Suffolk, NY 11743. Editor: Margaret Tempero MD, University of California, San Francisco Mission Bay Campus, 550 16th Street, 6th Floor, Box 3211, San Francisco, CA 94143. Managing Editor: Kimberly A. Callan MS ELS, National Comprehensive Cancer Network, 275 Commerce Dr, Ste 300, Fort Washington, PA 19034. 10. Owner: Full Name: Harborside Press LLC, John A. Gentile Jr (Principal), Anthony Cutrone (Principal), Conor Lynch (Principal). Complete Mailing Address: 94 North Woodhull Road, Huntington, Suffolk, NY 1174311) Known Bondholders, Mortgagees, and Other Security Holders Owning or Holding 1 Percent or More of Total Amount of Bonds, Mortgages, or Other Securities: None. 12) Tax Status: N/A.13) Publication Title: JNCCN_Journal of the National Comprehensive Cancer Network. 14) Issue Date for Circulation Data Below: July 2021.15) Extent and Nature of Circulation - Average No. Copies Each Issue During Preceding 12 Months. a) Total Number of Copies (Net press run): 25,879. b) Legitimate Paid and/or Requested Distribution (By Mail and Outside the Mail) (1) Outside County Paid/Requested Mail Subscriptions stated on PS Form 3541: 11,800. (2) In-County Paid/Requested Mail Subscriptions stated on PS Form 3541: N/A. (3) Sales Through Dealers and Carriers, Street Vendors, Counter Sales, and other Paid or Requested Distribution Outside USPS ${ }^{\circledR}$ : N/A. (4) Requested Copies Distributed by Other Mail Classes Through the USPS (e.g. First-Class Mail ${ }^{\circledR}$ ): 0 c) Total Paid and/or Requested CirculaRequested Distribution Outside USPS ${ }^{\circledR}$ : N/A. (4) Requested Copies Distributed by Other Mail Classes Through the USPS (e.g. First-Class Mail $\left.{ }^{\circledR}\right): 0$ c) Total Paid and/or Requested Circula-
tion (sum of 15b (1), (2,), (3), and (4): 11,800. d) Nonrequested Distribution (By Mail and Outside the Mail) (1) Outside County Nonrequested Copies Stated on PS Form 3541: 11,893. (2) In-County Nonrequested Copies Stated on PS Form 3541: N/A. (3) Nonrequested Copies Distributed Through the USPS by Other Classes of Mail: N/A. (4) Nonrequested Copies Distributed Outside the Mail: 137 e) Total Nonrequested Distribution (Sum of 15d (1), (2), (3) and (4)) 12,163. f) Total Distribution (Sum of 15c and e): 23,830. g) Copies not Distributed: 2,049. h) Total (Sum of $15 \mathrm{f}$ and g) 25,879. i) Percent Paid and/or Requested Circulation: 50\%15) Extent and Nature of Circulation - No. Copies of Single Issue Published Nearest to Filing Date. a) Total Number of Copies (Net press run): 25,644. b)Legitimate Paid and/or Requested Distribution (By Mail and Outside the Mail) (1) Outside County Paid/Requested Mail Subscriptions stated on PS Form 3541: 12,012. (2) In-County Paid/Requested Mail Subscriptions stated on PS Form 3541: N/A. (3) Sales Through Dealers and Carriers, Street Vendors, Counter Sales, and other Paid or Requested Distribution Outside USPS ${ }^{\circledR}$ : N/A. (4) Requested Copies Distributed by Other Mail Classes Through the USPS (e.g. First-Class Mail $\left.{ }^{\circledR}\right)$ : 0. c) Total Paid and/or Requested Circulation (sum of 15b (1), (2,), (3), and (4): 12012. d) Nonrequested Distribution (By Mail and Outside the Mail) (1) Outside County Nonrequested Copies Stated on PS Form 3541: 11, 167. (2) In-County Nonrequested Copies Stated on PS Form 3541: N/A. (3) Nonrequested Copies Distributed Through the USPS by Other Classes of Mail: N/A. (4) Nonrequested Copies Distributed Outside the Mail: 90. e) Total Nonrequested Distribution (Sum of 15d (1), (2), (3) and (4)) 11,257. f) Total Distribution (Sum of 15c and e): 23,269. g) Copies not Distributed: 2,375. h) Total (Sum of $15 \mathrm{f}$ and g) 25,644. i) Percent Paid and/or Requested Circulation: 52\%.16) Total circulation does not include electronic copies.17) Publication of Statement of Ownership for a Requester Publication is required and will be printed in the September 2021 issue of this publication. 18) Signature and Title of Editor, Publisher, Business Manager, or Owner: John A. Gentile Jr, Publisher. Date: $9 / 15 / 2021$. I certify that all information furnished on this form is true and complete. I understand that anyone who furnishes false or misleading information on this form or who omits material or information requested on the form may be subject to criminal sanctions (including fines and imprisonment) and/or civil sanctions (including civil penalties). 